IMAGINATION, COGNITION AND PERSONALITY, Vol. 31(4) 297-312, 2011-2012

\title{
PSYCHOPHYSIOLOGICAL COHERENCE AS A FUNCTION OF MENTAL IMAGERY PRACTICE
}

\author{
ULAS KAPLAN, ED.D. \\ James Madison University \\ GERALD N. EPSTEIN, M.D. \\ American Institute for Mental Imagery
}

\begin{abstract}
In this experimental study, we explored effects of mental imagery practice on psychophysiological coherence, measured as heart rhythm coherence. A total of 82 undergraduates participated in the study and were randomly assigned to mental imagery, thought monitoring, and control groups. The experiment took a period of 3 weeks, during which the first group regularly practiced two imagery exercises, and the second group practiced a thought monitoring exercise. Participants in all three groups visited a lab, twice a week, where their heart rhythm coherence was measured by a device that monitors heart rate variability. Results showed significant increases in heart rhythm coherence as a function of mental imagery practice. The effects of thought monitoring practice were much more limited. Methodological limitations of the study were discussed particularly in terms of the regulation of thought monitoring practice. Suggestions for future study include manipulating possible sources of variation in the effectiveness of imagery practice, and making connections between the cognitive study of imagery and its therapeutic function.
\end{abstract}

Image is the natural and universal language of the mind (Epstein, 1989). That is, this three-dimensional representation occurring inwardly is non-verbal, silent, and not logically structured as is outwardly expressed discursive language. As image is

(C) 2012, Baywood Publishing Co., Inc.

doi: 10.2190/IC.31.4.d

http://baywood.com 
a language, such as is found in Egyptian hieroglyphics, or even in the more abstract pictographic ones of Chinese and Hebrew, it is meant not only to be read and understood, but also to exert an influence on our behavior and psychophysiological responses.

Given this understanding, we can look to the early medical — and now becoming increasingly recognized - model existing before the shift in Western thinking starting about 450 years ago. This model viewed consciousness as a unitary phenomenon where mind and body exist as an irrevocable unit, each reflecting the other simultaneously (Berman 1981; McMahon, 1976). The dormancy of this earlier model has been reawakened (Berman, 1981), and with it renewed interest in the mind-body connection (Epstein, 1980) and the therapeutic effects of such an approach (Epstein, 1981; Siegel, 1986; Simonton, Simonton, \& Creighton, 1978).

Thus, mental imagery has been widely used as a therapeutic tool in facilitating health, performance, and well-being (Epstein, 1989). Studies exploring its possible benefits and effectiveness have focused on a wide range of conditions such as asthma (Epstein, Halper, Barrett, Birdsall, McGee, Baron, et al., 2004), cancer (Goodwin, Lee, Puig, \& Sherrard, 2005), respiratory functioning (Golla, Hutton, \& Grey Walter, 1943), athletic performance (Warner \& McNeill, 1988), and general well-being.

The focus of the present study is the role of mental imagery practice on psychophysiological coherence. According to the Institute of HeartMath Research Center, psychophysiological coherence is associated with "sustained positive emotion, high degree of mental and emotional stability, constructive integration of the mental and emotional systems, and increased synchronization and harmony between the cognitive, emotional and physiological systems" (McCraty, Atkinson, \& Tomasino, 2001, p. 17). It is a state or process of dynamic equilibrium within and between the organism's psychological and biological systems.

A central indicator of this psychophysiological balance and resilience is heart rhythm coherence, which represents an optimal combination of order and variability in the functioning of the heart. Also referred to as heart rate variability (HRV) coherence or "cardiac coherence" (Ginsberg, Berry, \& Powell, 2010), heart rhythm coherence represents "a stable, sine-wave-like pattern in the heart rate variability waveform" (McCraty, Atkinson, Tomasino, \& Bradley, 2009, p. 23), the mode of which was distinguished with a frequency around $0.1 \mathrm{~Hz}$. It reflects the organism's degree of control regarding "parasympathetic cardiac deceleration" and "has cardinal importance for the individual's attention and affect regulation" (Ginsberg et al., 2010, p. 52). Heart rhythm coherence has been identified with an optimal degree of HRV that is neither too low, nor too high. Under the coherent mode, the heart operates with sufficient consistency as well as variability for the flexibility and resilience of a well-functioning organism. The higher the heart rhythm coherence within a given time period, the closer the 
HRV is to an optimal range of functioning. Thus, high heart rhythm coherence represents increased psychophysiological balance, resilience, and well-being (McCraty et al., 2009).

Researchers showed that there is a close connection between heart rhythm patterns and emotional functioning (McCraty, Atkinson, Tiller, Rein, \& Watkins, 1995; McCraty et al., 2001). Different emotions are identified with distinct heart rhythm patterns, and different degrees of heart rhythm coherence. When this insight is combined with the role of the heart in regulating autonomic nervous system activity, heart rhythm coherence appears to be a key process by which emotions are connected to physical health. More specifically, the sustained experience of positive emotions such as compassion and gratitude is associated with high degrees of heart rhythm coherence, which facilitates psychological well-being, cognitive functioning, and physical health through increased parasympathetic activity (McCraty \& Childre, 2010). This therapeutic and developmental value of heart rhythm coherence has recently been supported by studies with combat veterans experiencing PTSD and active duty soldiers without PTSD (Ginsberg et al., 2010), and children with ADHD (Lloyd, Brett, \& Wesnes, 2010).

The central role of sustained positive emotions in psychophysiological coherence has practical significance in its promise to generate a number of positive health outcomes. In their review of literature, McCraty et al. (2009) identified various physical health benefits of practices based on positive emotions and attitudes, reflected in increased psychophysiological coherence.

Thus, psychophysiological coherence has a central role in human physical and psychological health and performance. Therefore, understanding the factors that improve it can have significant implications in a wide range of therapeutic and developmental domains. While mental imagery and heart rhythm coherence have been explored in separate studies, we believe that heart rhythm coherence is an ideal context of health, which mental imagery not only is applicable to, but also could improve significantly. Hence, the study aims to make this previous unexplored link by connecting mental imagery practice to the functioning of the heart and psychophysiological coherence.

In this context, we explored the following research questions in the present study:

a) Are there baseline level increases associated with mental imagery in heart rhythm coherence?

b) How does mental imagery practice affect immediate-i.e., treatment levelheart rhythm coherence?

Associated with mental imagery practice, we expected to see increases in baseline coherence levels and greater improvements in treatment levels of heart rhythm coherence. 


\section{METHOD}

\section{Participants}

A total of 82 undergraduate students (19 males and 63 females) at a university in the eastern United States participated in this study. The majority of students at this institution, and hence the sample, came from middle-class Caucasian families. Participants chose to join the study as one of the options for partial fulfillment of their course requirement. Participants were randomly assigned to one of three groups: control, mental imagery, and thought monitoring.

\section{Measures}

In this study, our outcome variable was heart rhythm coherence, which has been identified as "the key marker of the psychophysiological coherence mode" (McCraty et al., 2009, p. 23). During seven testing sessions throughout a period of 3 weeks, each participant's heart rhythm coherence was measured numerically out of a score of 100 by using the EmWave PC System that was developed by the HeartMath Institute. The EmWave PC is a computer-integrated system that uses a finger or an ear sensor to detect heart rhythm frequency. This is transformed into heart rate variability (HRV) coherence scores in the form of low, medium, and high coherence percentage values. In the present study, high coherence percentage of each measurement period was taken as the coherence score.

Participants also completed a survey that included items for various measures of psychological well-being and development. These measures are not included in the present article.

\section{Procedure}

At the beginning of the study, all participants completed the Epstein Balloon test (Epstein et al., 2004), which assesses ability to image. In this test, participants were asked to close their eyes, and complete three cycles of breathing, and imagine: (a) a table; (b) a box; and (c) many colors of uninflated balloons inside the box. Participants were asked to report how many of these three items they were able to imaginally see. Only two participants reported not being able to image any of the three items. During the random assignment, one of these participants had been in the control, the other in the imagery group. The participant who had been assigned to the imagery group was later switched to the control group. During the balloon test, three participants reported being able to image two of the three items; and the rest of the participants were able to image all three items.

Participants also provided saliva samples in a test-tube at the beginning and end of study for cortisol measurements. However, because of complications in measurement of cortisol levels, this exploration was removed from the study. 
The study took 3 weeks before students' final exam period. Participants visited the lab for a brief testing session twice a week, and one final measurement at the end of the study. Participants had some flexibility in choosing which 2 days of a given week they could be tested. On the other hand, the testing schedule was regulated so that each participant's two testing sessions within a week was 2 or 3 days apart. Still, for participants whose schedules did not match this structure on a certain week, an exception was made by allowing them to be tested on consecutive days.

For each participant, HRV data was collected individually. During each testing session, participants sat on a chair in front of the computer in the presence of a trained researcher who used the EmWave PC instrument. At the beginning of each lab visit, each participant's baseline heart rhythm coherence level was measured for a period of 1 minute. The same duration was applied to the thought monitoring treatment level measurement. We considered this to be a sufficient and reasonable standard duration for all baseline measurements and the thought monitoring treatment level measurement (involving the repetition of a mental affirmation). This is because: (a) EmWave PC takes into account variations in coherence and provides an average coherence measure for any given session, and (b) the imagery exercises were each expected to take around 1 minute or slightly longer.

The baseline measurement for all participants was followed by a second coherence measurement (another 1 minute), which included another baseline measurement for the control participants, while the imagery group participants practiced the first imagery exercise, and the thought monitoring group participants practiced a self-chosen mental affirmation that they repeated in their minds. The mental imagery participants underwent a third heart rhythm coherence measurement as they practiced the second imagery exercise. The initial training and testing session for imagery participants took around 30 minutes. Overall, the length of heart rhythm coherence testing sessions were around 7 minutes for control, 12 minutes for thought monitoring, and 18 minutes for imagery participants. This experimental procedure is presented in Table 1.

\section{Control Group}

Participants in the control group were subject to the same lab testing schedule as the treatment groups. During each testing session, each control group participant provided two coherence measurements. Each of these measurements was taken with the EmWave PC system, and lasted for 1 minute. The first measurement was taken in order to obtain baseline level coherence comparisons between groups, involving measures prior to the exercises for the mental imagery and thought monitoring groups. The second measurement for the control group participants was taken in order to compare with the treatment level measurements for the mental imagery and thought monitoring groups. This additional coherence measurement for the control group was to control for any possible effect of 
Table 1. Experimental Procedure Outlining What the Participants Did During Testing Sessions for Control, Imagery, and Thought Monitoring Group Participants

\begin{tabular}{llll}
\hline Group & $\begin{array}{l}\text { First coherence } \\
\text { measurement }\end{array}$ & $\begin{array}{l}\text { Second coherence } \\
\text { measurement }\end{array}$ & $\begin{array}{l}\text { Third coherence } \\
\text { measurement }\end{array}$ \\
\hline Control & $\begin{array}{l}\text { Sitting on a chair } \\
\text { for 1 minute }\end{array}$ & $\begin{array}{l}\text { Sitting on a chair } \\
\text { for 1 minute }\end{array}$ & Practicing the \\
$\begin{array}{l}\text { Mental } \\
\text { imagery }\end{array}$ & $\begin{array}{l}\text { Sitting on a chair } \\
\text { for 1 minute }\end{array}$ & $\begin{array}{l}\text { Practicing the blue- } \\
\text { light exercise }\end{array}$ & $\begin{array}{l}\text { anti-stress } \\
\text { exercise }\end{array}$ \\
$\begin{array}{l}\text { Thought } \\
\text { monitoring }\end{array}$ & $\begin{array}{l}\text { Sitting on a chair } \\
\text { for } 1 \text { minute }\end{array}$ & $\begin{array}{l}\text { Repeating in their minds a } \\
\text { mental affirmation for 1 minute }\end{array}$ \\
\hline
\end{tabular}

comfort with the testing situation during the second (treatment) measurement for the mental imagery and thought monitoring groups.

\section{Mental Imagery Group}

Participants in the imagery group learned the exercise during the first testing session in person by a psychiatrist, who is an expert on mental imagery. This initial session took an average of 30 minutes. Because of scheduling challenges, five mental imagery participants had the initial training from this trainer over the phone, while the rest of the imagery participants learned the practice in person. Following the first training session, during which baseline and treatment HRV coherence levels were obtained, participants practiced two exercises (blue-light and anti-stress, in this order) every morning for a period of 3 weeks. The two exercises that participants practiced each morning and during testing sessions are presented in Table 2.

\section{Thought Monitoring Group}

During their first testing session, thought monitoring participants were instructed to practice a five-step procedure (Grayson, 2003) as a shortened version of cognitive therapy exercises. This practice required identifying their thoughts when they feel disturbed during the day, and replace the negative thought with a positive affirmation. They were asked to remember to use this exercise everyday whenever they experience an unpleasant feeling. During the testing sessions, the thought monitoring participants did not go through the five steps; rather, their treatment HRV coherence was measured while they only repeated the positive affirmation in their mind, with their eyes closed. A major purpose in introducing this additional level of measurement was to have an additional-treatment-level 
Table 2. Imagery Exercises Used in the Study

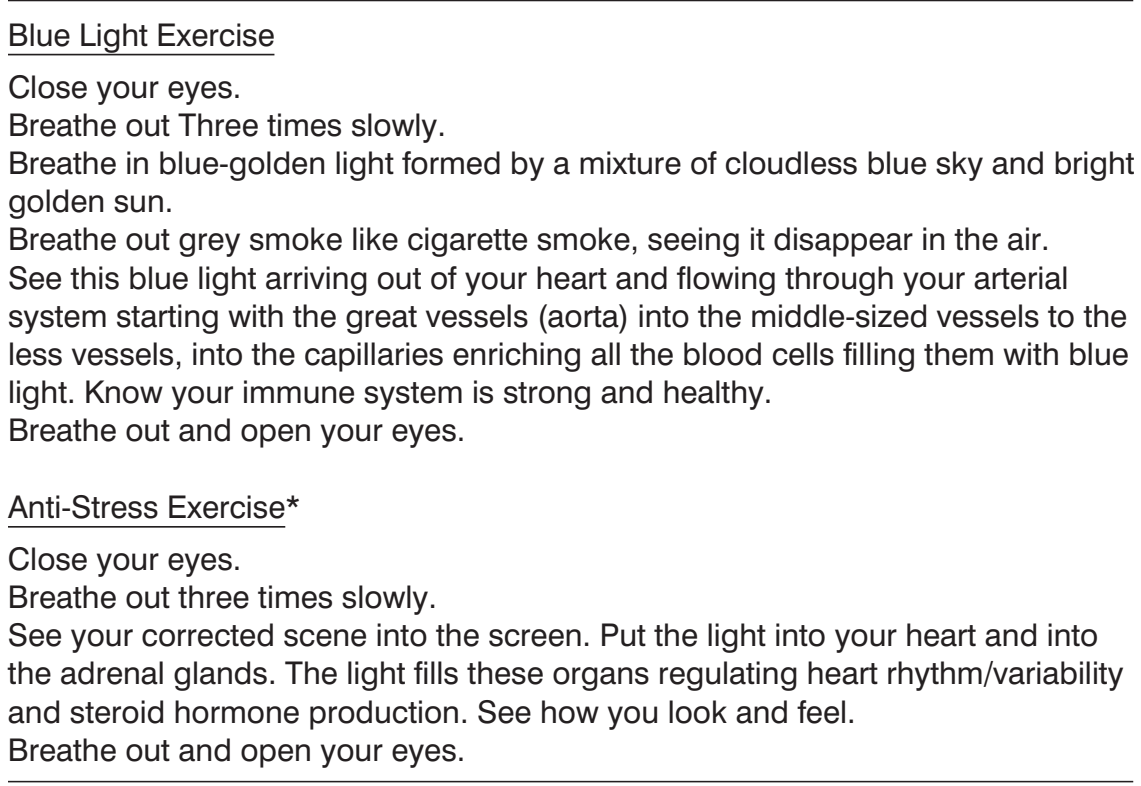

*Note: During the training session, participants were asked to imagine a distressing memory on a screen, and reverse or correct it. After this initial session, the exercise involved only imagining the corrected scene.

of comparison with mental imagery practice. We believed that examining the impact of mental imagery not only in contrast to a control group, but also relative to an alternative treatment based on a cognitive intervention, could be additionally informative regarding its therapeutic value.

\section{RESULTS}

In order to address the first research question, average baseline HRV coherence levels were calculated, as presented in Figure 1.

An Analysis of Variance (ANOVA) was carried out to compare groups for each of the seven measurement days. Bonferroni correction was made on the basis of seven comparisons. As a result, only session 3 baseline HRV coherence measurements revealed a statistically significant difference between groups, $F(2,77)=5.48, p=.006$. Scheffe post-hoc analysis comparing groups showed that the HRV coherence for the mental imagery group was significantly higher than that of the control group $(p=.009)$ and the thought monitoring group $(p=.051)$.

In order to address the second research question, the procedure used for the first question was applied to treatment HRV coherence levels. Treatment coherence 


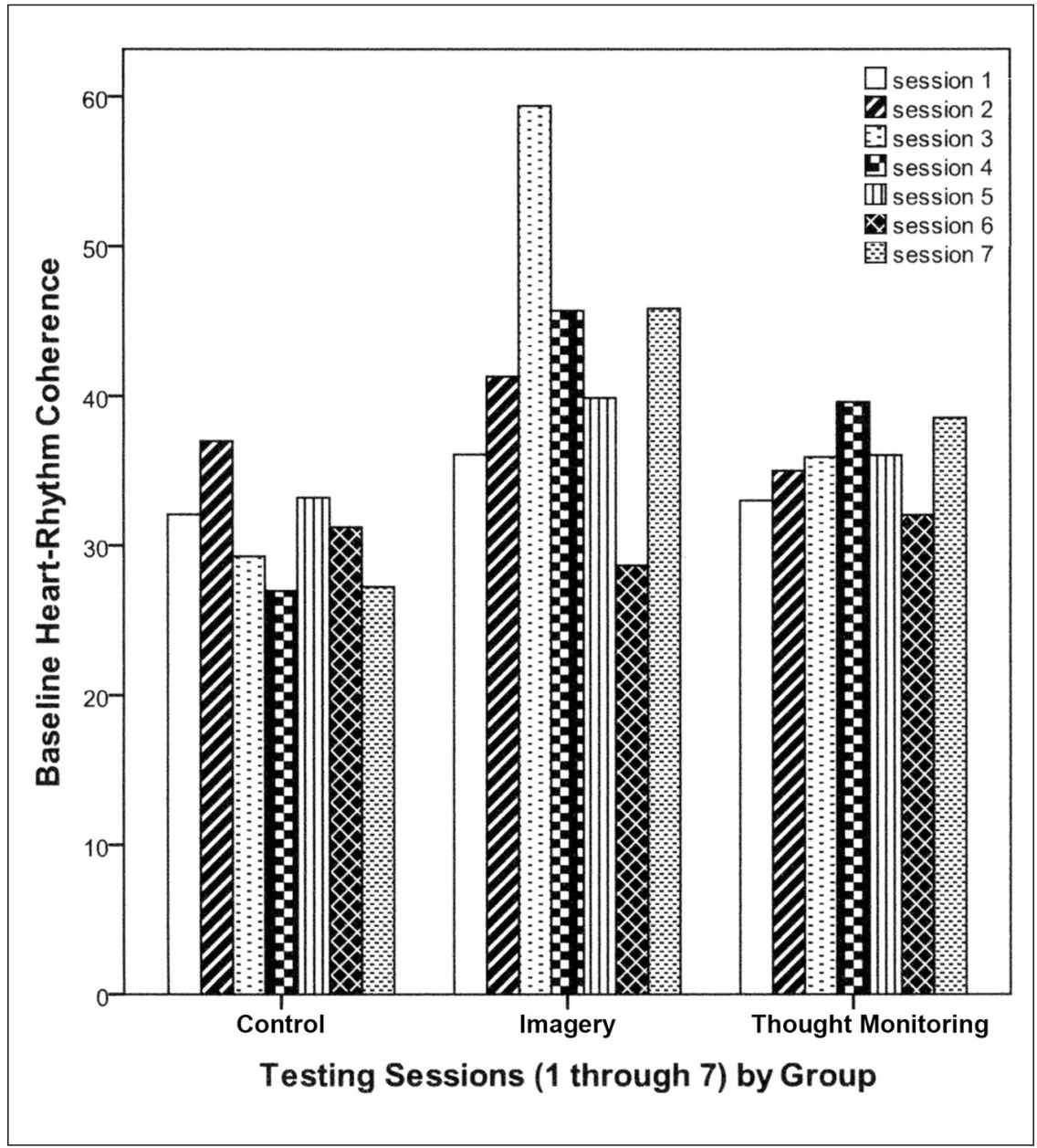

Figure 1. Baseline HRV coherence averages for each of the seven measurement days throughout 3 weeks for control, imagery, and thought monitoring groups, indicating measurements taken when imagery and thought monitoring groups are not practicing their exercises.

levels included a second-baseline-measurement for the control group, two different measurements for the imagery group (one for blue-light and another during the anti-stress exercise), and one measurement for the thought monitoring group (during the repeated practice of affirmation from the thought monitoring exercise). The average treatment HRV coherence levels for the control, imagery, and the thought monitoring groups are presented in Figure 2 for each of the 


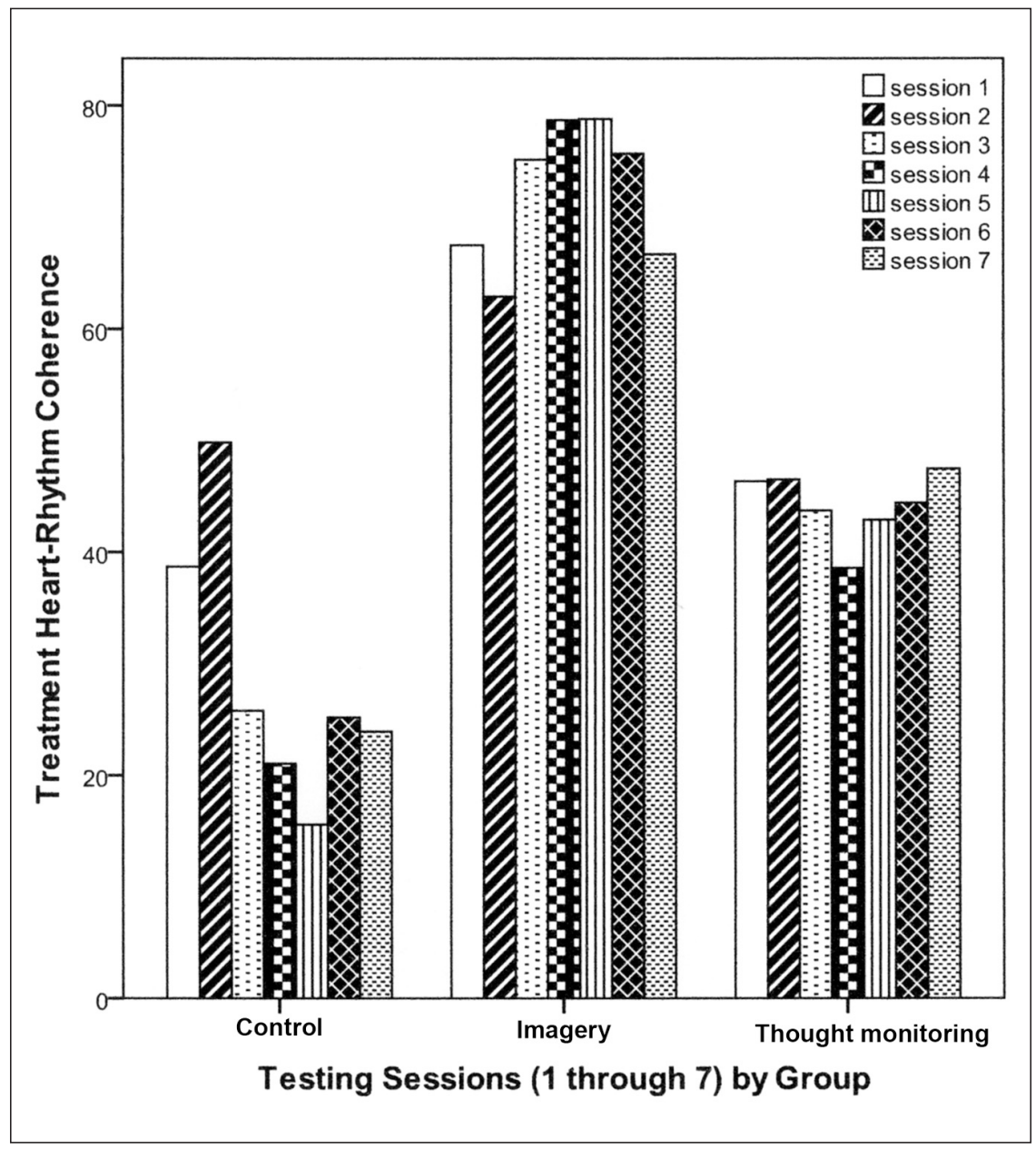

Figure 2. HRV Coherence averages for each of the seven measurement days throughout three weeks for control, imagery and thought monitoring groups, indicating measurements taken when imagery group is practicing the blue light exercise, and thought monitoring participants are repeating a mental affirmation.

Note: HRV values used in the treatment comparisons for the control group participants are based on a second measurement during each testing session, following the first measurement that was used in the baseline comparisons. 
7 days of measurement. In this graph, imagery group is represented by measurements during the first (blue light) exercise.

In order to test for statistical significance, two Analyses of Covariance (ANCOVA) were conducted for each of the 7 days of measurement, one for the comparison involving blue light, and the other involving the anti-stress exercise. In these comparisons between the three groups, the baseline coherence levels were taken as covariates. In other words, the comparisons of treatment conditions were conducted controlling for any differences in baseline coherence levels. Using the Bonferonni correction, a much more strict level of significance than usual was taken $(.05 / 14=.0036)$. The results of these analyses are presented in Table 3.

Table 3 reveals that the blue light exercise led to significantly higher heart rhythm coherence for sessions 4, 5, and 6, and anti-stress exercise produced higher coherence for session 4. In addition, it is important to note that for sessions 1, 3, and 7 the blue light exercise, and for session 5 the anti-stress exercise, revealed higher treatment level coherence at .01 or .05 levels, which ceased to be significant when the Bonferroni correction was applied.

\section{DISCUSSION}

The current study is part of a research direction using the mind-body perspective by exploring the relationship between the image language and possible significant effects that can be recorded quantitatively. In this process, we investigated a previously unexamined connection between mental imagery and heart rhythm coherence. As a result, we found that mental imagery practice can increase psychophysiological coherence reflected in heart rhythm patterns. This was consistent with previously emphasized effects of mental imagery on psychological and physical well-being (Epstein, 1989; Epstein et al., 2004; Taylor, Pham, Rivkin, \& Armor, 1998). This effect was particularly strong for immediate coherence benefits, as measured during the imagery practice on testing sessions.

While baseline heart rhythm coherence for the imagery group participants was overall higher than that of the control participants (except for testing session 6), only session 3 revealed a statistically significance different in baseline coherence. Thus, the increases in baseline heart rhythm coherence in our sample were overall not strong enough to infer possible differences in the population. On the other hand, the immediate effects of mental imagery practice on psychophysiological coherence were more robust throughout the 3-week period. In other words, while mental imagery practice appears highly promising in shifting the individuals' psychobiology into an increased state of balance, harmony, and resilience, our study does not provide strong enough evidence that this positive effect on well-being can be enduring throughout the day when participants do not repeat their imagery practice.

Still, our findings confirm the value of exploring biofeedback mechanisms in the "psychophysiology of imagery and healing" (Schwartz, 1984, p. 35). In 
PSYCHOPHYSIOLOGICAL COHERENCE AND MENTAL IMAGERY ／ 307

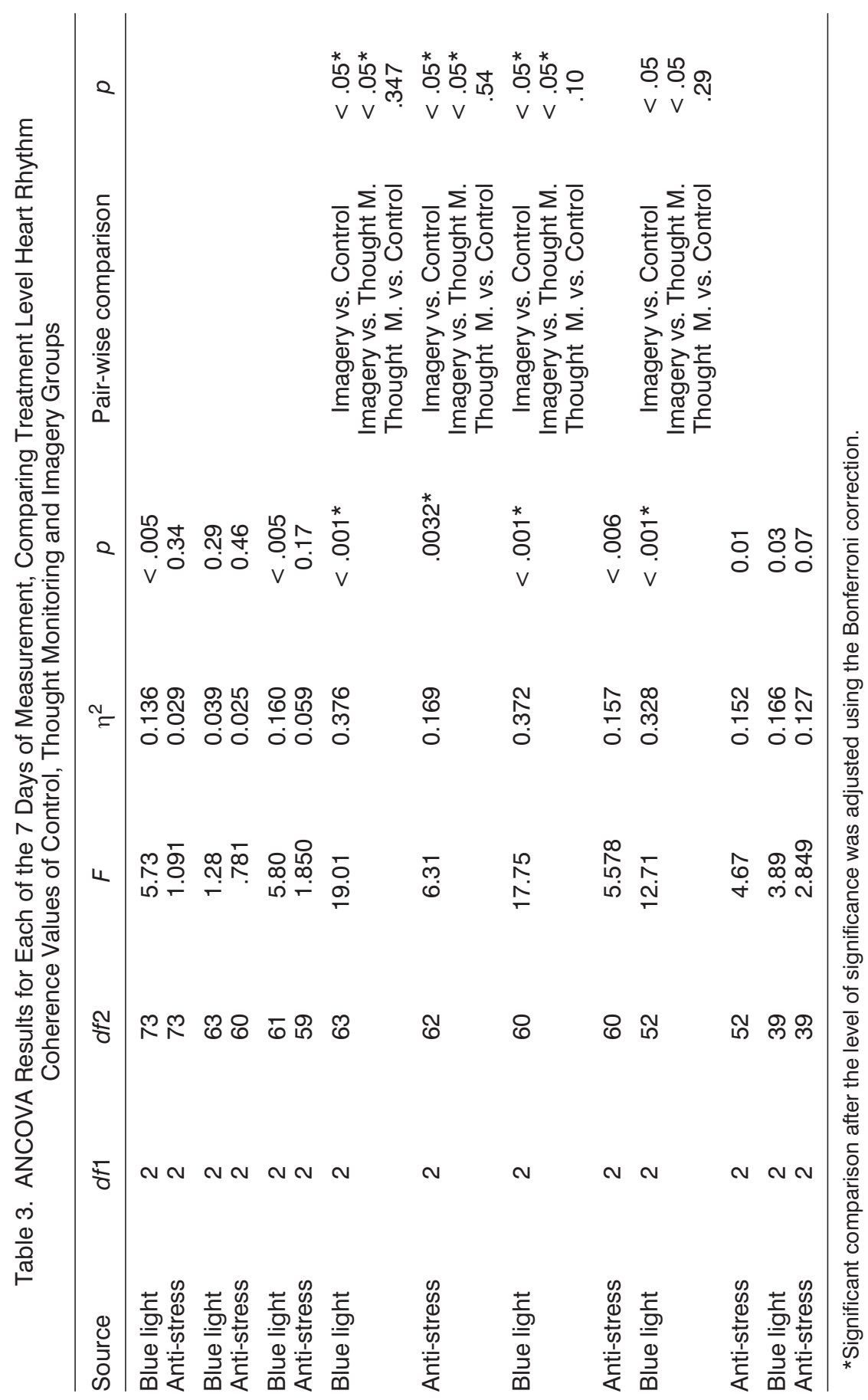


this process, imagery as a psychological process was found to create desirable shifts in biological processes, measured as heart rhythm coherence.

One unanticipated finding was the differential impact of the two imagery exercises. The blue-light exercise appeared to be much more effective in increasing heart rhythm coherence than did the anti-stress exercise. This difference is significant in highlighting the impact of the specific components of imagery practice. Three differences between the two exercises may have contributed to their differential coherence benefits. First, the blue light exercise has a more comprehensive focus on physiological functioning, including specific emphasis on the immune system, vessels, and blood cells. Second, the blue light exercise itself can be seen as more coherent and integrated around this physiological improvement direction. On the other hand, the anti-stress exercise starts with an experiential component (imaging a corrected version of a distressing experience) that for many participants may have felt fragmented or isolated from its emphasis on the heart. Third, the blue-light exercise was completely uniform across participants. While the anti-stress exercise was mostly standardized, it had an individualized component ("the corrected scene") unique to each participant. This partial subjectivity could have led to significant variability in the effectiveness of the exercise across participants.

Individual differences of subjectivity in the anti-stress exercise notwithstanding, our design did not measure or control for the difference of subjective experience in mental imagery. This aspect of our study is a potentially strong source of variation that has divided scholars in their approach to mental imagery (Kunzendorf \& Sheikh, 2010). The present study was based on an objective approach, including a standard exercise for all participants to be measured quantitatively. Hence, the effects observed are notable considering this limitation. Future studies incorporating the subjective perspective could individually adjust the imagery exercise, monitor the experience of each participant, and obtain self-reports of their subjective experience. Such new research directions connecting the objective and subjective perspectives of studying mental imagery could illuminate the individual and as well the procedural sources of variation in the effectiveness of mental imagery in physical and psychological well-being.

The thought monitoring group experienced much more limited HRV coherence effects of their practice than did the imagery participants. None of the testing sessions revealed a significant difference for the baseline HRV levels for this group, compared to the control group. While treatment HRV coherence of this group was usually higher than their baseline HRV coherence average (except for session 4), only session 1 revealed a statistically significant difference at the .05 level, and session 2 comparison was significant at the .10 level. This fact that the effects were limited can be attributed to several factors in addition to the practice itself. First, the thought monitoring participants' practices were not as standardized as the imagery exercises. Second, there was a lack of experimental reinforcement of participants' practice. Third, unlike the first mental imagery 
practice, the content of thought monitoring practice did not focus on the heart or physiological functioning. Still, the limited effects recorded are still promising for further study, as they show the possible immediate psychophysiological coherence benefits of repeating mental affirmations. The small benefits observed in this study could be more robust if the consistency and frequency of thought monitoring practice are much more regulated and reinforced.

Hence, a major limitation of this study is the lack of effective control or regulation of thought monitoring practice throughout the 3 -week period. This is partly due to the nature of the thought monitoring practice requiring a more widespread commitment throughout the day than does the imagery practice, which only required remembering to do it every morning. Stronger experimental reinforcement of this practice could involve asking participants to record the number of times they used the exercise each day, and/or send a text message each time the exercise is used. This way, a future study could involve a more valid measurement of the effects of regular thought monitoring practice.

Similarly, in terms of the effects of mental imagery, one possible explanation of the discrepancy between the strong psychophysiological coherence gains during the exercises and the weaker baseline HRV coherence effects is the frequency of practice. Considering that the immediate well-being effects of imagery practice are strong, and there are some enduring effects, it is plausible that with increased frequency of practice, the enduring effects (i.e., baseline HRV coherence increases) could become more pronounced. Hence, future studies in which participants could practice imagery two or three times a day, rather than only in the morning, could reveal the extent to which stronger effects in baseline coherence levels are possible.

Another limitation of the study is lack of control regarding physiological conditions that could affect HRV. Thus, controlling for body mass index, medical conditions, and the use of possible medications that influence HRV could be useful in future studies. Such controls could be particularly important for studies in which the number of participants in each experimental condition is relatively small, as in the present study. Furthermore, the fact that each testing session did not occur on the same day for all participants (e.g., the third session was the Monday for some participants, whereas Tuesday for others), and the existence of many missing values (not all participants completed all seven testing sessions) increased the methodological limitations of the study.

By focusing on psychophysiological coherence, this study builds on and contributes to a body of literature exploring various healing benefits of mental imagery (Sheikh, 1984, 2003). In addition to the possibilities mentioned above, two future research directions are particularly promising in relation to heart rhythm coherence. The first direction involves manipulating potential sources of variation in the practice of mental imagery, such as vividness, degree, and the quality of experienced affect, as well as the quality, content, and the frequency of the imagery exercise. Second, studies that aim to integrate 
an understanding of the cognitive processes regarding mental imagery (Kosslyn, 1994; Kosslyn, Ganis, \& Thompson, 2006; Kunzendorf \& Reynolds, 2004-2005) with its therapeutic effects in terms of psychophysiological coherence can be insightful. In this process, researchers and practitioners could better understand the specific conditions that could improve the effectiveness of imagery practice, as well as its formative and contributing cognitive and emotional mechanisms.

\section{REFERENCES}

Berman, M. (1981). The Re-enchantment of the world. Ithaca: Cornell University Press.

Epstein, G. N. (Ed.). (1980). Studies in non-deterministic psychology. New York: Human Sciences Press; (1997, NY: ACMI Press).

Epstein, G. N. (1981). Waking dream therapy. Dream process as imagination. New York: Human Sciences Press; (1997, NY: ACMI Press).

Epstein, G. N. (1989). Healing visualizations. New York: Bantam Books.

Epstein, G. N., Halper, J. P., Barrett, E. A. M, Birdsall, C., McGee, M., Barron, K. P., et al. (2004). A pilot study of mind-body changes in adults with asthma who practice mental imagery. Alternative Therapies, 10(4), 66-71.

Ginsberg, J. P., Berry, M. E., \& Powell, D. A. (2010). Cardiac coherence and PTSD in combat veterans. Alternative Therapies in Health and Medicine, 16(4), 52-60.

Golla, F., Hutton, E. L., \& Grey Walter, W. (1943). The objective study of mental imagery (1). Physiological concomitants. Journal of Mental Science, 89, 216-223.

Goodwin, L. K., Lee, S. M., Puig, A. I., \& Sherrard, P. A. D. (2005). Guided imagery and relaxation for women with early stage breast cancer. Journal of Creativity in Mental Health, 1(2), 53-66.

Grayson, H. (2003). Mindful loving. 10 practices for creating deeper connections. New York: Gotham Books.

Kosslyn, S. M. (1994). Image and brain. The resolution of imagery debate. Cambridge, MA: MIT Press.

Kosslyn, S. M., Ganis, G., \& Thompson, W. L. (2006). Mental imagery and the human brain. Neural, Cognitive and Developmental Issues, 1, 195-209.

Kunzendorf, R. G., \& Reynolds, K. (2004-2005). On the cognitive function of visual images and the development of individual differences. Imagination, Cognition and Personality, 24(3), 245-257.

Kunzendorf, R. G., \& Sheikh, A. A. (2010). Mental imagery. In I. B. Weiner \& W. E. Craighead (Eds.), The Corsini encyclopedia of psychology (pp. 983-985). New York: Wiley.

Lloyd, A., Brett, D., \& Wesnes, K. (2010). Coherence training in children with attentiondeficit hyperactivity disorder: Cognitive functions and behavioral changes. Alternative Therapies in Health and Medicine, 16(4), 34-42.

Marks, D. F. (1973). Visual imagery differences in the recall of pictures. British Journal of Psychology, 64, 17-24.

Marks, D. F. (1999). Consciousness, mental imagery and action. British Journal of Psychology, 90, 567-585. 
McCraty, R., Atkinson, M., \& Bradley, R. T. (2004). Electrophysiological evidence of intuition: Part 2. A system-wide process? Journal of Alternative and Complementary Medicine, 10(2), 325-336.

McCraty, R., Atkinson, M., \& Lipsenthal, L. (2000). Emotional self-regulation program enhances psychological health and quality of life in patients with diabetes (Publication No. 00-006). Boulder Creek, CA: HeartMath Research Center, Institute of HeartMath. Retrieved from http://www.heartmath.org/research/rp-emotional-selfregulation-program-enhancespsychological-health.quality-of-life-in-patients.html

McCraty, R., Atkinson, M., Lipsenthal, L., \& Arguelles L. (2003). Impact of the power to change performance program on stress and health risks in correctional officers (Report No. 03-014). Boulder Creek, CA: HeartMath Research Center, Institute of HeartMath.

McCraty, R., Atkinson, M., Tiller, W. A., Rein, G., \& Watkins, A. D. (1995). The effects of emotions on short-term heart rate variability using power spectrum analysis. American Journal of Cardiology, 76(14), 1089-1093.

McCraty, R., Atkinson, M., \& Tomasino, D. (2001). Science of the heart: Exploring the role of the heart in human performance (Publication No. 01-001). Boulder Creek, CA: HeartMath Research Center, Institute of HeartMath. Retrieved from http://www.heartmath.org/research/science-of-the-heart.html

McCraty, R., Atkinson, M., Tomasino, D., \& Bradley, R. T. (2009). The coherent heart heart-brain interactions, psychophysiological coherence, and the emergence of system-wide order. Integral Review, 5(2), 10-115.

McCraty, R., \& Childre, D. (2010). Coherence: Bridging personal, social and global health. Alternative Therapies in Health and Medicine, 16(4), 10-24.

McCraty, R., \& Tomasino, D. (2004). Heart rhythm coherence feedback: A new tool for stress reduction, rehabilitation, and performance enhancement. In Proceedings of the First Baltic Forum on Neuronal Regulation and Biofeedback, Riga, Latvia. Retrieved from http://www.heartmath.org/research/publications.html

McCraty, R., \& Tomasino, D. (2006a). Emotional stress, positive emotions, and psychophysiological coherence. In B. B. Arnetz \& R. Ekman (Eds.), Stress in Health and Disease (pp. 342-365). Weinheim, Germany: Wiley-VCH.

McCraty, R., \& Tomasino, D. (2006b). The coherent heart: Heart-brain interactions, psychophysiological coherence, and the emergence of system wide order (Publication No. 06- 022). Boulder Creek, CA: HeartMath Research Center, Institute of HeartMath.

McMahon, C. (1976). The role of imagination in the disease process. Psychological Medicine, 6, 179-184.

McMahon, C., \& Sheikh, A. A. (1984). Imagination in disease and healing processes. In A. A. Sheikh (Ed.), Imagination and healing (pp. 7-34). Amityville, NY: Baywood.

Schwartz, G. E. (1984). Psychophysiology of imagery and healing: A systems perspective. In A. A. Sheikh (Ed.), Imagination and healing (pp. 35-50). Amityville, NY: Baywood.

Sheikh, A. A. (Ed.). (1984). Imagination and healing. Amityville, NY: Baywood.

Sheikh, A. A. (Ed.) (2003). Healing images. The role of imagination in health. Amityville, NY: Baywood.

Siegel, B. (1986). Love, medicine \& miracles. San Francisco, CA: HarperCollins.

Simonton, O. C., Simonton, S., \& Creighton, J. L. (1978). Getting well again. Los Angeles, CA: J. P. Tarcher. 


\section{2 / KAPLAN AND EPSTEIN}

Taylor, S. E., Pham, L. B., Rivkin, I. D., \& Armor, D. A. (1998). Harnessing the imagination. American Psychologist, 53(4), 429-439.

Warner, L., \& McNeill, M. E. (1988). Mental imagery and its potential for physical therapy. Physical Therapy Journal, 68(4), 516-521.

Direct reprint requests to:

Ulas Kaplan

Department of Psychology

James Madison University

MSC 7707

Harrisonburg, VA 22807

e-mail: kaplanux@jmu.edu 